\title{
Examining the Role of the Police in Reentry Partnership Initiatives
}

James M. Byrne

Don Hummer

The University of Massachusetts, Lowell

\section{Redefining Roles and Relationships}

The development of partnerships in law enforcement is not a new idea, but it does appear that today's police are much more likely to enter into partnerships than their predecessors, especially at the local level. One reason for this new collaborative mindset on the part of the nation's 21,143 police agencies (Maguire, et al., 1998) is the adoption of community policing in many of these jurisdictions. While a review of the research on the implementation and impact of community police reforms is beyond the scope of this article (for such review see, e.g., National Research Council, 2004), it is worth noting that community policing programs do represent a fundamental shift in strategy: rather than working alone (or in teams with other officers) patrol officers are encouraged to meet and work with community groups, personnel from social services, public health, and other criminal justice agencies to address the community's crime/order maintenance problems.

As part of this new collaborative orientation, partnerships between police and a wide variety of agencies and community groups, including state and local corrections, are encouraged as an appropriate problem-solving strategy. Critics of community policing have pointed out that one consequence of such collaboration is to increase the span of control of police agencies, particularly in disadvantaged areas. With the help of these new "partners," local police can collect better and more detailed intelligence on residents, expand the scope of searches, and target both individuals (e.g. gang members, sex offenders) and "hot spot" areas (e.g. crack houses) for removal from the community. As Manning (2003) has pointed out, short-term gains in order-maintenance in low income, inner-city areas may be followed by longterm losses (moral, social, political) in these same communities, due to the negative consequences of incarceration on offenders, their families, and the communities in which they reside (and to which they will return). The potential for such unintended consequences must certainly be considered in the types of police-corrections partnerships highlighted in this article.

In addition to community policing reforms, sentencing reform can certainly be considered as another compelling impetus for police-corrections partnerships. Due to our reliance on incarceration as the "sanction of choice" for many crime categories (particularly drug offenders), we now have over 2 million inmates in custody in the United States. Last year, 600,000 of these inmates were released from federal, state and local facilities, a three-fold increase from just 20 years ago (RAND Research Brief, 2003). Due to changes in "good time" provisions, tougher parole eligibility, and the establishment of mandatory minimum sentences, one in five of these new prison releasees were max-outs, which effectively means that they returned to the community without the supervision, services, and control provided by community corrections agencies (e.g. probation, parole).

Who (if anyone) should fill this supervision, service, and control void? In many jurisdictions, the surveillance and control responsibility appears to be moving to the local police, who are likely to view prison releasees as a logical target population, especially given the "fact" that, in all likelihood, two-thirds of these offenders will be rearrested (and half will be reincarcerated) for new crimes within three years (Langan and Levin, 2002). The provision of (voluntary) services for prisoners released without parole supervision is more problematic, but it does appear that both institutional and community corrections agencies are now beginning to recognize that they also need to expand their role and responsibility vis-à-vis this group of releasees. However, it is still unclear where the money will come from to fund services for these releasees, who appear to be falling through the cracks of the current service provision network. Whatever the source, adequate funding for the mental health, housing, substance abuse, and public health problems of this subgroup of releasees appears to be a key to the success of the partnership. For reentry programs developed through federal grant and/or funds from private foundations, it will be interesting to "follow the money" as it flows to various partnership agencies, because control of the funding for reentry will affect the nature, duration, and orientation (surveillance, treatment, control) of the partnership.

\section{An Overview of Police-Corrections Partnership Development in the United} States

Parent and Snyder (1999) conducted a nationwide review of the utilization of police-corrections partnerships; in conjunction with this review, they completed site visits at 19 separate partnerships located across five states (Minnesota, Washington, Connecticut, Arizona, California). According to the 
profiles included in the report, five different models of police-corrections partnerships can be identified:

(1) Enhanced supervision partnerships, in which police and probation or parole officers perform joint supervision or other joint functions related to offenders in the community....

(2) Fugitive apprehension units, in which police and correctional agencies collaborate to locate and apprehend persons who have absconded from probation or parole supervision....

(3) Information sharing partnerships, in which corrections and law enforcement agencies institute procedures to exchange information related to offenders...

(4) Specialized enforcement partnerships, in which police and correctional agencies, as well as community organizations, collaborate to rid communities of particular problems, and

(5) Interagency problem-solving partnerships, in which law enforcement and correctional agencies confer to identify problems of mutual concern and to identify and implement solutions to them (Parent and Snyder, 1999:7)

These five models offer different strategies and problem contexts for the application of police-corrections partnerships to the myriad of issues associated with offender reentry initiatives. Unfortunately, the authors of this report were unable to provide an estimate of the number of police-corrections partnerships currently in place in the United States that utilize at least one of these models.

\section{Police-Corrections Partnerships and Offender Reentry}

Partnerships between law enforcement and corrections agencies appear to be an emerging strategy adopted by several federal agencies (NIJ, NIC, OJJDP) that provide funding for a wide range of offender reentry initiatives at the federal, state, and local level. In several jurisdictions, partnership development is a prerequisite for federal funding of the initiative (Taxman, Young, and Byrne, 2003a). But from where did this new-found "faith" in partnership emerge? In the absence of empirical research, it appears that program developers have turned to another source: the experience of public sector managers involved in a wide range of problem-solving scenarios. A number of recent reviews of organizational effectiveness in the public sector (see, e.g., U.S. General Accounting Office, 2004 for an overview) have emphasized the importance of the strategic use of partnerships to address issues involving multiple agencies and systems. According to the participants at a recent GAO forum on this issue, "to be a high-performing organization,... Agencies must effectively manage and influence relationships with organizations outside of their direct control" (GAO:2004:9). When viewed in this light, police-corrections partnerships represent an attempt by two independent agencies to work together to solve a common problem. In the process, the question can certainly be raised: Who is influencing whom? At their core, police-corrections partnerships can be defined by the types of roles and relationships that emerge between/among participating organizations and agencies. Below, we examine "roles and relationships" across eight "model" reentry partnership initiatives identified by The Office of Justice Programs. ${ }^{1}$ These eight program models certainly do not represent the full range of reentry programs currently available across the country, ${ }^{2}$ but they do provide a solid analytic foundation from which we can examine the problems and potential inherent in police-corrections partnerships.

Despite fundamental differences in philosophy, background, and orientation toward offenders, police-corrections partnerships have the potential to enhance public safety, streamline service provision, and achieve common goals, such as crime reduction (Parent \& Snyder, 1999). They also may have unintended longer-term consequences for both offenders and communities that must be examined before we move further in this area. As described below, the Reentry Partnership Initiative (RPI) is an example of a cooperative effort to maximize law enforcement and correctional resources in a meaningful way to address a specific target issue (offender reentry). Developed by the Office of Justice Programs of the Federal Department of Justice, RPI programs form a partnership of criminal justice, social service, and community groups to develop and implement a reentry process. A key component for a successful RPI is linking local law enforcement with other agencies and actors responsible for offender reintegration. By working in conjunction with corrections personnel, and extending partnerships to include other agencies, police can enhance their presence in target neighborhoods and in the process generate support for collaborative efforts from policymakers and the general public (Parent \& Snyder, 1999).
In the following section we describe the specific role of law enforcement in collaborating with representatives of corrections agencies, as well as with other key actors within the Reentry Partnership Initiative (community, treatment providers, victim, and offender). In doing so we demonstrate the pivotal role that police have in implementing a successful "shared decision-making" partnership for offender reintegration, while also highlighting potential problems inherent in this strategy.

\section{Identifying the Role of Police at Each} Key Phase in the Reentry Process

Local police departments have played a critical role in the development of the RPI model in several sites across the country. In an earlier review of eight "model" reentry programs completed by Taxman, Young, and Byrne (2003a), three key phases of the RPI model are described in detail: the institutional phase, the structured reentry phase, and the community reintegration phase (see figure 1). Based on their detailed reviews of reentry initiatives in eight separate jurisdictions (Maryland, Vermont, South Carolina, Missouri, Florida, Nevada, Massachusetts and Washington), we can describe and discuss the role of the police at each of these phases of reentry. ${ }^{3}$ We have examined similarities and differences across these eight jurisdictions in the nature, type, duration, and intensity of police involvement in each phase of the offender reentry process. It is our hope that such a review will provide critical information to program developers interested in the applicability of police-corrections partnerships to the complex problems associated with offender reentry.

\section{The Role of Policing during the Institutional Phase of Reentry}

During the institutional phase of an offender reentry program, a number of decisions have to be made about offenders that involve local law enforcement, both directly and indirectly. Consider, for example, the selection of the target population for a new reentry program. Although the timing of the decision varied from jurisdiction to jurisdiction, local police departments have been involved in the selection of the RPI target population at several sites. The rationale underlying this strategy is fairly straightforward: The decision regarding whom to include and exclude from a particular reentry program should be made by the entire partnership, rather than one specific agency. By sharing decision-making vis-à-vis the targeting 
Figure 1:

Reentry Partnership Continuum

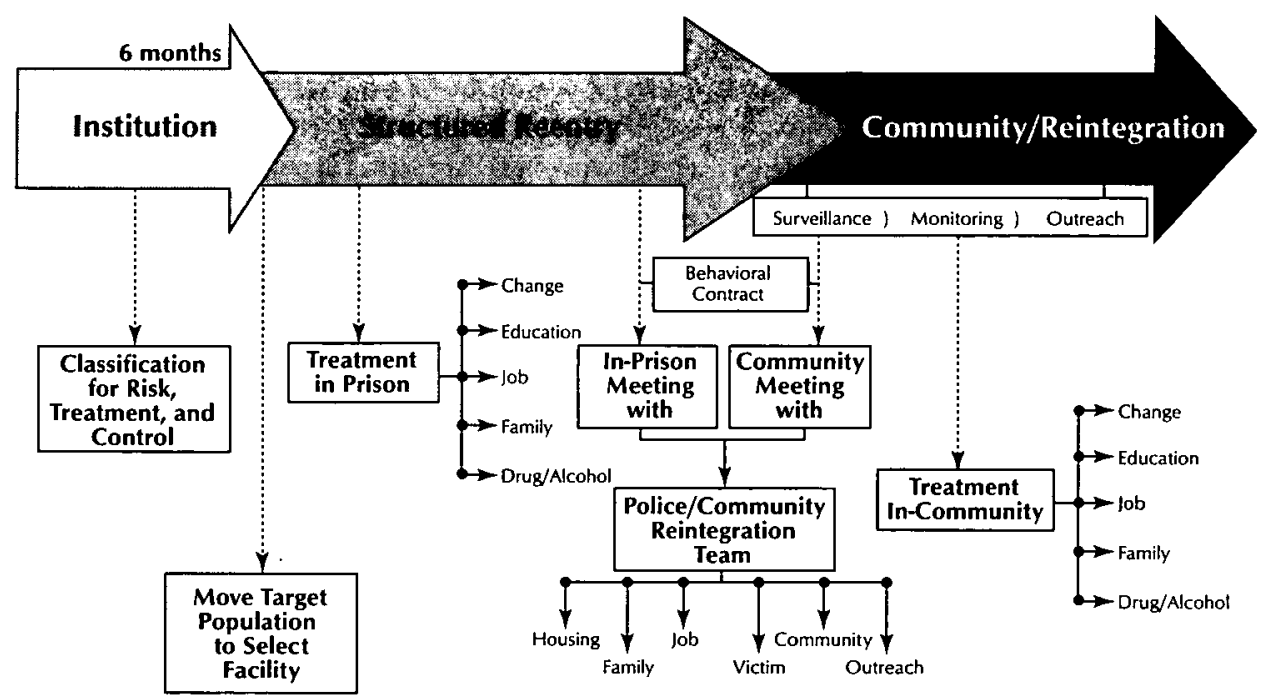

issue, program developers have increased the likelihood of police support for-and partial ownership of - the reentry initiative.

The dangers inherent in allowing a single agency (e.g. institutional corrections) to determine program eligibility were highlighted in the review of Las Vegas, Nevada's reentry program, in which only offenders from specific "weed and seed" areas were targeted. The police chief refused to participate in the program because of the fear that the program was tantamount to racial profiling; only high minority concentration neighborhoods were being targeted for the partnership reentry effort.

The police chief's fear was based on the possibility/likelihood that offenders reentering these targeted neighborhoods will face much closer police scrutiny (i.e. stops, surveillance, etc.) than offenders released to other areas of the city. If such "scrutiny" leads to higher rearrest, reconviction, and/or return-to-prison rates for offenders released to high minority concentration areas, then the negative consequences of this "placebased" targeting decision would be substantiated. However, no such research was conducted at this site, since the RPI program was only in its initial development stage. Rather than implement the reentry program and then monitor the comparative rearrest, reconviction, and return to prison rates of releasees citywide, the chief made a simple suggestion: expand the program beyond the initial "weed and seed" target sites, in order to "broaden" the population targeted for "potential" police profiling. community corrections personnel, employers). They were also expected to respond proactively to this information (e.g. increased face-to-face personal contacts, focusing on specific issues related to the victim, progress in treatment, employment, housing, etc.), based on the notion that this type of police-initiated response might be effective, especially when it focused on an individual offender's progress addressing the problems that resulted in his/her most recent incarceration (i.e., substance abuse, mental illness, employment, family problems). But despite such benevolent intentions, it is certainly possible that offender targeting represents yet another manifestation of the profiling problem. Once again it is Peter Manning (2003) who offers the most succinct summary of the research on police profiling:

The data are overwhelming-people of color, no matter what their presence on the roads, work, or past record, are disproportionately stopped, searched, arrested, charged, and imprisoned (Meehan and Ponder, 2002a,b; Walker, Spohn, and DeLone, 1996) (55).

In addition to their role in offender targeting decisions, police may also be able to assist in other decisions made during the institutional phase of RPI, such as offender classification, institutional location, and institutional treatment. Local police have information about offenders that may be shared with institutional staff involved in offender classification and placement, such as peer/gang associations, family history and the nature of the commitment offense. In addition, police at one site (Vermont) serve on local community "restorative justice" boards that review and approve the offender's institutional treatment plan within 45 days of incarceration. While only one of the eight sites we visited includes the police in decisions regarding institutional treatment (for substance abuse, anger management, and/or other behavioral issues), it can certainly be argued that the police have a stake in offender treatment decisions. By including police in the treatment decision-making process, Vermont's RPI program developers have given police officers an opportunity to see, first-hand, how offenders change and the value of treatment interventions throughout the system.

\section{The Role of Policing during the Structured Reentry Phase}

The second phase of the RPI model involves structured reentry to the community. Police have an important role in decisions during 
this second phase of reentry. Typically, the structured reentry phase of RPI programs focuses on the last few months before release and the first month after release. It is during this period that an offender reintegration plan is developed and a number of basic decisions are made about when the offender will be released, whether specific release conditions will be established, where the offender will live and work, and how the offender will address his/her ongoing treatment needs. Depending on the jurisdiction we visited, police were involved in one or more of these structured reentry decision points.

Perhaps the most controversial and innovative structured reentry strategy that involves police is the use of community boards (in Vermont) to review the offender's progress in treatment and to make release recommendations. Since local police departments are represented on these boards, they will have input on release decisions and in some cases, the conditions of release. It will be interesting to track the impact of community boards on release decisions in this jurisdiction and to observe the court's response to the inevitable challenges to the authority of these community boards to essentially make early release (i.e. parole) decisions.

In several jurisdictions, the police will meet with the offender in prison to discuss his/her pending release. The purpose of this meeting is twofold: first, to explain to offenders how local policing has changed since they were initially incarcerated, due to the current emphasis on community policing (and crime prevention); and secondly, to let offenders know that the police will be watching them upon release, monitoring their progress in treatment, and that they will not be anonymous. Will one meeting between the offender and a neighborhood police officer deter the offender from criminal behavior upon release? We doubt it, but there is more involved here than an attempt to "scare" an offender straight. In Lowell, Massachusetts, for example, the police meet with the offender in conjunction with the local treatment provider, who describes the types of treatment programs available for offenders returning to this community. It is the dual message-treatment and control-that the offender hears at this meeting. Equally important, the meeting establishes an essential partnership between local police and treatment providers that will continue for the remainder of the offender's stay in the reentry program.

Another facet of the police role during the structured reentry process is the contact- between the police and the offender during the first few days after the offender has been released from prison. For offenders released conditionally, police surveillance and contact serves as a supplement to probation and parole supervision. For offenders released unconditionally, police surveillance and contact represents the only formal offender control mechanism. As we noted earlier, since over 20 percent of offenders nationwide leave prison without probation or parole supervision, there does appear to be an immediate need for an expanded police role for these offenders. We anticipate that in some jurisdictions-such as the Lowell, Massachusetts, RPI (in this state, over half of prison releasees have maxed-out)-police will be in contact with local treatment providers and thus will know who is - and who is not-participating in treatment, which may affect the nature and timing of police-offender interactions. In other jurisdictions (e.g. Spokane, Washington) police will meet regularly with volunteer, community "guardians," who will provide assistance to offenders immediately upon release from prison (helping with housing, transportation, etc.), placing them in a unique position to assess offender progress during reentry. In these jurisdictions, it appears that police departments have begun to fill the void created by sentencing reform generally and mandatory sentencing in particular.

Finally, one jurisdiction developed a unique strategy for improving the community surveillance and control capacity of local police. In conjunction with the State Department of

Figure 2:

Overview of Structured Reentry Phase
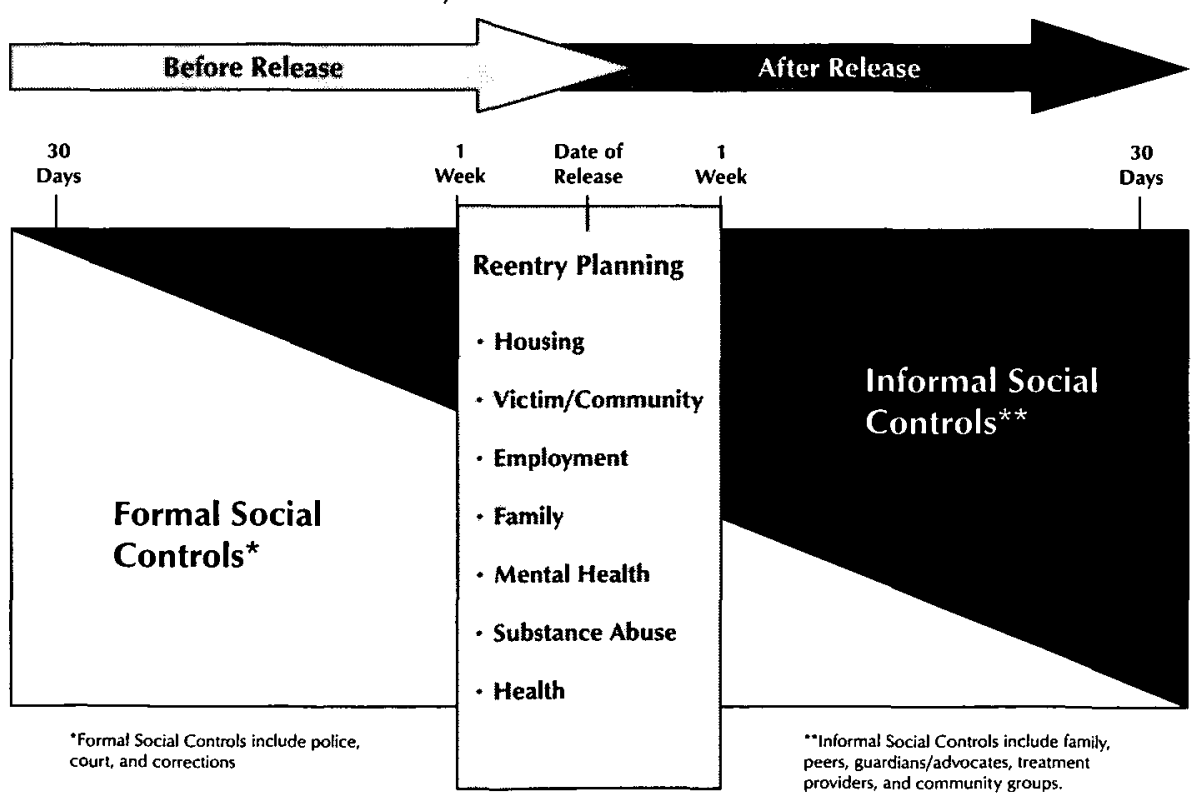

Corrections, the crime analysis unit of the Lowell police department develops "profiles" of each offender released from prison and returning to the Lowell community each month, which are displayed at roll call. These profiles include the offender's most recent picture, criminal record, gang affiliations (if any), and nature of his/her last offense. This is certainly one possible strategy for reducing the anonymity of offenders returning to the community by increasing police awareness of the reentering offender population.

\section{The Role of the Police During the Community Reintegration Phase}

The third phase of the RPI model is the community reintegration phase, which emphasizes long-term offender change, an elusive goal for the corrections system. The underlying assumption of RPI program developers is that during this final phase of reentry, there will be a transition from formal to informal social control mechanisms, such as the offender's family, peer group, faith-based community groups, employers, guardians, and other community members. The response of the police to reentry offenders during this final phase is likely to vary according to the behavior of the offender. For example, if the offender is employed and participating in treatment, then the police department's interaction with the offender will likely be minimal. However, offenders who have difficulty with the initial transition from prison to home will likely face much more intensive police interven- 
tion (both formal and informal). In Burlington, Vermont, and Spokane, Washington, for example, the police work in conjunction with local community corrections staff to conduct curfew checks on targeted offenders both by home visits and stops at targeted locations (e.g.. bars, street corners). Police may also act informally by simply talking with "at-risk" offenders-those who appear to be having trouble finding a job, suitable housing, and/ or receiving treatment for mental health or substance abuse problems. It appears that the police have a role in the community reintegration phase that will change over time based on the behavior of the offender and the specific features of the reentry program examined.

\section{The Police and Institutional Corrections}

When we think about tie police, it is usually in the context of offender control, not offender change. But police departments in RPI jurisdictions view their role somewhat differently: they are involved in both offender control and offender change activities. In Vermont, for example, police serve on local community boards that review and approve each offender's institutional treatment plan, which was developed by the offender (in conjunction with prison program staff) within 45 days of incarceration. They are also involved in reviewing the offender's progress in treatment and in the development of a structured reentry plan. While Vermont is unique in terms of the police role in institutional treatment, the police are actively involved in prerelease planning in several jurisdictions (e.g. Massachusetts, Washington, and Maryland).

RPI programs require that police act in new ways toward the offender, not only upon release but also while incarcerated. For example, police officers at several sites actually visited the offender while in prison to discuss the police department's role in the reentry program. In the Lowell, Massachusetts program, a neighborhood police officer meets with the offender in prison about a month before the offender is scheduled to return to the officer's neighborhood. Importantly, the officer does not attend this meeting alone; he/ she comes as part of a neighborhood reentry team that also includes a local treatment provider. The utilization of a police-community treatment provider "partnership" team within an institutional setting represents a new role for police in the institution. At the meeting, the neighborhood police officer describes how the police department has changed in recent years in this community, due in large part to two factors: 1) community policing, and 2) more cops on the street. The officer then focuses on his/her dual role as a resource person/problem-solver and community surveillance/control officer. The "message" that the offender receives is that the police are there to help the offender, but that they will do their "helping" within the broader context of public safety. In the name of public safety, police officers will not allow offenders to return to the community anonymously; informal surveillance of reentry offenders will occur. Massachusetts is not the only site to employ this strategy; other sites using similar approaches include Washington, Maryland, South Carolina, and Missouri.

Police will also interact with institutional corrections staff in a wide variety of activities directly related to offender reentry. First, meetings with offenders in prison must be coordinated through the state's department of corrections. Next, the development of offender profiles to be used by local police will require information to be shared by the research staffs of the releasing institution and the police department (e.g., current offenses, criminal history, institutional behavior, gang affiliations, specific release conditions). Third, the target population selected for the program should reflect police preferences. And finally, police may participate on community boards that have a direct impact on release decisions and/or the conditions of release. In Vermont, for example, offenders are expected to develop (individual) offender responsibility plans, which are reviewed by restorative justice boards comprised of a wide range of community members, including the police.

When the topic of prison release is raised, it is usually within the context of judicial and/or parole decision-making. However, it can certainly be argued that police departments should have a role in release decisions as well, in such areas as the timing of the release, the offender's location in a particular community, and the determination (where applicable) of release conditions. Once again, it is Burlington, Vermont's restorative justice model that provides the framework for this type of active police participation in the structured release process. In Vermont's RPI model, police serve on community boards that review the offender's individual responsibility plan approximately one month prior to the offender's proposed release date. If the offender has made progress addressing the problem/need areas identified in the plan, then the community board will likely recommend release; but if the offender has not made sufficient progress then the board would not likely support release. In essence, the local community board-with active police involvement-will be acting as a parole board at this site.

\section{The Police and Treatment Providers}

As we noted above, the role of the police in the reentry process will change not only with respect to police-offender interactions, but also in the nature and extent of policetreatment provider interactions. For many officers, this program provides them with their first opportunity to work directly and collaboratively with treatment providers. For both parties, this new partnership will likely require some intensive cross-training during the program's initial stages, because both the police and the treatment provider come from such different backgrounds and skill orientations. In such partnerships, role conflict is inevitable.

For the RPI program to be effective, this type of ongoing role conflict will have to be addressed. At one site we visited, for example, treatment staff expressed concern that offenders would not agree to participate in (voluntary) treatment programs upon release, because they believed that offenders would have trouble "trusting" the treatment providers if they arrived at the meeting together with the police. It is possible that such concerns are valid; it is also possible that they actually reflect the treatment provider's orientation toward police, not the offender's perspective. In any event, information sharing between police and treatment providers appears to be an essential feature of a reentry program where differential police surveillance and control is triggered by an offender's progress in treatment.

\section{The Police and Community Corrections}

In the eight programs we examined, we see indications of a fundamental change in the nature and extent of the interaction between police and community corrections personnel (e.g., probation/parole). In Spokane, Washington, for example, police and community supervision officers are physically located in the same "cop shops," where they often share information on offenders under community supervision. In Vermont, police and community corrections officers conduct joint "curfew checks" on reentry offenders, targeting specific locations in the community (e.g., bars) where offenders may be located. In Las 
Vegas, Nevada, community supervision officers focus exclusively on the surveillance and control aspects of community supervision. Since these community supervision officers also have police "arrest" powers (and training), it could be argued that in this jurisdiction, the line between community police and community supervision officers is becoming blurred.

In Massachusetts, the Lowell police department's intelligence unit creates "posters" for each offender released to the community each month, which are hung up in the police station for officers to view at roll call. It is assumed that this information will result in an increased level of informal surveillance by police in target communities and that the results of these surveillance activities will be shared with the community supervision officers who work in this area.

In South Carolina, officers from the police and sheriff's department contact offenders immediately upon release from prison, either by phone or by home visit. The purpose of this contact is twofold: first, to demonstrate the "helping role" of police by identifying available community resources and services; and second, to reinforce the surveillance and control role of local police. It certainly appears that the role of local police is to enhance (or supplement) community supervision among conditional releasees, while taking primary responsibility for those inmates released unconditionally.

\section{The Police and the Community}

RPI programs have affected the way police departments interact with local community residents and groups, including crime victims. At two sites-Missouri and Vermont-neighborhood police officers sit on local community boards that make a wide range of decisions affecting offenders both directly and indirectly. In Washington, police departments work with volunteer "guardians," who assist offenders in a variety of areas (e.g., transportation, job preparation, housing, etc.), while also acting as another set of "eyes and ears" for the police. In Vermont, and Missouri, police officers serve on restorative justice boards involved in all aspects of institutional treatment and community reintegration. As these examples illustrate, the role of the police in the community has certainly been expanded to include both informal social control strategies (e.g., the use of guardians) and the pursuit of community justice initiatives. Will such an expanded police role improve the reentry prospects of offenders or will it have potentially detri- mental consequences for both the offenders and communities? At this point in the design, implementation, and evaluation process, the answer to this question is clear: we don't know. For this reason, it is critical that we examine the impact of this new wave of reentry programs on both targeted offenders (e.g. re-arrest, reconviction, re-incarceration) and targeted communities (e.g. crime rates, disease rates, poverty rates).

\section{The Police and the Victim}

The police play an important role in reentry, not only in the areas of offender surveillance and control, but also in the provision of services to victims and families of victims. Victims of crime have problems and needs that are only partially addressed when the alleged offender is arrested. An examination of clearance rates [i.e., the number of reported crimes cleared by the arrest of the offender(s)] reveals that most jurisdictions do a pretty good job of making an arrest when the reported crime was a crime against a person (with clearance rates usually around 50 percent); they are not nearly as effective when it is a property crime (20 percent clearance rates). Since only a fraction of all arrested offenders are convicted and incarcerated, it is not surprising that community residents ask the police for help with the "offenders walking among us" (e.g., dispute resolution, formal and informal surveillance, active investigation). Since 9 out of 10 offenders who enter prison eventually get out, it seems logical that crime victims would ask the police for help with these offenders as well, especially when the offender has "maxed-out" of prison.

Victims of crime may need information on when the offender is being released and where he/she is planning to reside. They may want assistance in resolving ongoing disputes with the offender and his/her family and friends. They may also want increased police surveillance and protection. Finally, they may ask police assistance in filing restraining orders against the offender, especially if child protection and/or domestic violence is an issue. While getting out of prison is "good news" for the offender, it is a time of great anxiety and stress for many crime victims, friends, and family. In the past, victims could turn to community corrections for help and assistance; now, the role and responsibility appears to have moved to the police, particularly for those offenders released unconditionally from prison or jail.

\section{The Police and the Offender}

For some observers, it may seem paradoxical that police departments are now active partners in offender reentry initiatives, since these same departments were actively involved in removing these offenders from the community in the first place. To others, however, police-corrections partnerships represent an attempt to address the underlying causes of criminal behavior, by focusing on a variety of individual-level and community-level problems that have been linked to criminality.

At the individual level, offenders are often afflicted with multiple problems, including drug addiction, alcoholism, communicable disease, and mental illness. As a recent RAND Research Brief highlighted, “....almost 25 percent of state prisoners released by year-end 1999 were alcohol-dependent, 14 percent were mentally ill, and 12 percent were homeless at the time of arrest (2003:1). RAND researchers go on to report that offenders released from prison have an 8 to 9 times higher prevalence rate for HIV (compared to the general population), a 9 to 10 times greater prevalence rate for Hepatitis C, a 5 times greater prevalence rate for AIDS, and a 3 to 5 times greater prevalence rate for serious mental illness (i.e. schizophrenia or other psychotic disorders). For many of these offenders, substance abuse has been a significant, long standing problem (National Commission on Correctional Health Care, 2002). Unless these individual-level problems are addressed, it seems inevitable that this month's releasees will be next month's rearrests and next year's "new" prison admissions.

Of course, the types of individual-level problems just described cannot be addressed without recognizing their broader community context (see e.g., Sampson, Raudenbush, and Earls, 1997). Community-level problems include unemployment, income inequality, inadequate housing, homelessness, and ineffective informal social control networks (i.e. family, school, church, neighborhood). The police-corrections partnerships highlighted in this review appear to recognize the need to address problems at both the individual and community level. However, it is still unclear exactly how the "zero tolerance" policing strategies commonly associated with the "Broken Windows" version of community policing (Kelling and Coles, 1996; Bratton, Wilson, Kelling, Rivers, and Cove, 2004) will coexist with RPI program initiatives designed to provide housing, treatment, services, and support to targeted offenders. ${ }^{4}$ Ultimately, 
the success of police-corrections partnerships may hinge on the ability of local police to work simultaneously on crime prevention and crime control initiatives, and in the process, to resolve the conflicts inherent in current "broken windows" policing strategies.

A proactive, problem-solving approach is at the core of police-offender interactions in reentry jurisdictions. In the RPI model, police visit offenders in prison prior to release rather than waiting until the offender is back on the street. Utilizing the latest offender profile data, police know who is returning to their community before they are released. And when police interact with offenders once they return to the community it is before not after, a problem occurs or there is a call for service. It will likely take some time for offenders to realize that the role of the police in reentry jurisdictions has changed and that police are now involved in activities (related to housing, employment, and treatment) that can help offenders turn their lives around (Taxman, Young and Byrne, 2003b). However, offenders must also recognize that the police will know where offenders live, which offenders are in treatment, and whether they are employed; and that they will adjust their surveillance and control activities based on this information. It remains to be seen whether the policeoffender interactions associated with reentry initiatives will have their intended effect, both on individual offender change and community-level order maintenance.

\section{Conclusion}

The police-corrections partnerships described in this article represent an important shift in both the philosophy and practice of prisoner reentry. Given the inherent conflict associated with the interests of police and institutional corrections vis-à-vis offender reentry (after all, police remove offenders from the community and corrections send them "home" again, often to the same community), it is remarkable that these programs have emerged and appear to be successful, at least in terms of implementation. ${ }^{5}$ However, a number of issues related to the expanded role of police in the offender reentry process still need to be resolved, including 1) the potential for racial profiling, inherent in offender/community targeting decisions, 2) the limits of information sharing across agencies, (in particular, between police and treatment providers), and 3) the impact of this expanded role for police on both offenders released from prison and jail and the communities to which they return. Similarly, both institutional and community corrections agencies will have to consider their own need for role redefinition, particularly regarding offenders who "maxout" of prison and return to the community without the surveillance, services, and control provided by traditional community corrections agencies. Police departments across the eight jurisdictions we visited appear to be filling the void created by sentencing reforms, but the long-term consequences of this expanded police role-for both offenders and the communities targeted for reentry -have yet to be evaluated.

\section{Selected References}

Bratton, William, J.Q. Wilson, G. Kelling, R.E. Rivers, and P. Cove (2004) "This works: Crime Prevention and the Future of Broken Windows Policing" Civic Bulletin 35:1-14.

Byrne, J.M., Taxman, F.S. \& Young, D. (2003) Emerging Roles and Responsibility in the Reentry Partnership Initiative: New Ways of Doing Business. National Institute of Justice: Washington, DC.

Harrison, P and Beck, J. (2003) Prisoners in 2002 Washington, D.C.: U.S. Department of Justice, Office of Justice Programs, Bureau of Justice Statistics, NIC 200248.

Langan, P. and Levin, D. (2002) Recidivism of Prisoners Released in 1994. Washington, D.C. U.S. Department of Justice, Bureau of Justice Statistics NCI 193427.

Maguire, Edward (1997) "Structural Change in Large Police Organizations" Justice Quarterly 14:547-76.

Manning, Peter (2003) Policing Contingencies (Chicago, Illinois: University of Chicago Press).

Manning, P. (2001) "Theorizing Policing: The Drama and Myth of Crime Control in the NYPD" Theoretical Criminology 5:315-344.

Maruna, S. and Immarigeon, R, editors (2004) After Crime and Punishment: Pathways to Offender Reintegration. Portland, Oregon: Willan Publishing.

Meehan, A and M. Ponder (2003a) "How Roadway Composition Matters in Analyzing Police Data on Racial Profiling" Police Quarterly 5:306-333.

Meehan, A. and M. Ponder (2002b) "Race and Place: The Ecology of Racial Profiling African American Drivers" Justice Quarterly 19:399-430.

National Commission on Correctional Health Care (2002) The Health Status of Soon-ToBe-Released Inmates, Volume I Washington, D.C., Office of Justice Programs.

National Research Council (2004) Fairness and Effectiveness in Policing. Washington, D.C. National Academy Press.
Parent, D. \& B. Snyder (1999). Police-Corrections Partnerships. National Institute of Justice: Washington, DC.

Rand (2003) "Prisoner Reentry: What Are the Public Health Challenges?" RAND Research Brief. Santa Monica, CA: RAND, RB-6013-PSJ.

Sampson, Robert, S. Raudenbush, and F. Earls (1997) "Neighborhoods and Violent Crime" Science, 227:918-24.

Taxman, F.S., Young, D. \& Byrne, J.M. (2003a). From Prison Safety to Public Safety: Best Practices in Offender Reentry. National Institute of Justice: Washington, DC.

Taxman, F.S., Young, D. \& Byrne, J.M. (2003b). Offender's Views of Reentry: Implications for Processes, Programs, and Services. National Institute of Justice: Washington, D.C.

Taxman, F.S., J. Byrne and D. Young (2002). Targeting for Reentry: Matching Needs and Services to Maximize Public Safety. National Institute of Justice: Washington, D.C.

U. S. General Accounting Office (2004). HighPerforming Organizations: Metrics, Means, and Mechanisms for Achieving High Performance in the 21st Century Management Environment. GAO-04-343SP. Washington, D.C. February, 2004.

Walker, S., C. Spohn, and M. DeLone (1996) The Color of Justice. Belmont, CA: Wadsworth.

\section{Endnotes}

1. This article has been adapted from a report prepared for The National Institute of Justice, Office of Justice Programs. Emerging Roles and Responsibilities in the Reentry Partnership Initiative: New Ways of Doing Business, James Byrne, Faye Taxman and Douglas Young (Aug. 2001).

2. For more detail on the research highlighted in this article, see the series of articles prepared for NIJ under grant 2000IJCX0045 and available from NCJRS.

3. The eight case studies of model Reentry Partnership Initiative (RPI) programs were conducted in the spring, 2001 by an evaluation team directed by Faye Taxman, University of Maryland, who served as the principle investigator of the NIJ-sponsored evaluation. The site visits were conducted by Dr. Taxman (Florida, Massachusetts, South Carolina, Maryland), Dr. Byrne (Massachusetts, Vermont, Maryland, Nevada, and Washington), Doug Young (Maryland, Missouri, Washington), Meredith Thanner (Nevada, South Carolina), Dr. Anspach (Vermont), and Dr. Holsinger (Missouri). Copies of individual site evaluations can be obtained by contacting either Faye Taxman or James Byrne.

4. Consider, for example, the problem of subway crime. Kelling has argued that the main cause of subway crime in New York City was lawlessness, not homelessness, and "it didn't take much time to end that culture once you figured out what the problem was" (2004:8). The problem with Kelling's conceptualization is that it suggests that police can maintain order in the subway without addressing the homelessness problem of these "lawless" individuals. A very different approach to this problem would be taken by police in the reentry programs we visited; in many jurisdictions, there would be a zero- 
tolerance policy on homelessness among releasees from prison, not on minor subway crime.

5. Despite the recent research attention focused on the offender reentry issue (see, e.g. Maruna and Immarigeon, editors, 2004 for an overview), we know remarkably little about the impact of adult reentry programs on either offenders or communities (see, Petersilia, this issue, for a preliminary review). 